\title{
Píldoras Second Round. Cápsulas audiovisuales para incentivar las artes y los videojuegos en educación secundaria \\ Second Round Pills. Audiovisual Capsules to encourage the Arts and Video Games in Secondary School
}

\author{
Ricard Huerta ${ }^{1}$ \\ ricard.huerta@uv.es \\ ${ }^{1}$ Instituto de Creatividad e Innovaciones \\ Educativas \\ Universitat de València \\ Valencia, España
}

\begin{abstract}
Resumen- La investigación analiza los resultados de una propuesta de innovación impulsada para fomentar las artes en secundaria. La iniciativa "Second Round" aglutina los esfuerzos de varias universidades y centros de secundaria en los que llevamos seis años favoreciendo la indagación en temáticas emergentes, mediante nuevos espacios de integración creativa. Durante el curso 2020-2021, a causa de las circunstancias extraordinarias provocadas por la pandemia de COVID-19, se optó por incorporar la reflexión sobre aspectos como los videojuegos, cómic e ilustración. Entre las aportaciones de este proceso destacamos la creación de un conjunto de cápsulas audiovisuales, en las que especialistas y docentes, tanto de la universidad como de secundaria, exponen sus puntos de vista, abarcando cuestiones de actualidad, e implicando a creativos actuales. Con este tipo de iniciativas estamos logrando acercar entornos tradicionalmente distantes, como son los departamentos universitarios y los institutos de secundaria, potenciando así la cooperación entre ambos, generando al mismo tiempo recursos para el alumnado y el profesorado que incorporan tecnologías digitales. En las opiniones recogidas mediante encuestas y análisis de resultados, coordinando también grupos focales, detectamos que la labor está sirviendo para contagiar de energía tanto al profesorado como al alumnado.
\end{abstract}

\section{Palabras clave: Videojuegos, Secundaria, Educación Artística, Creatividad, Tecnología digital}

Abstract- This research analyzes the results of an innovation proposal created to promote the arts in secondary school. The "Second Round" project joins the efforts of several universities and secondary schools. For six years we have been promoting research on emerging issues, through new spaces for creative integration. During the 2020-2021 academic year, due to the extraordinary circumstances caused by the COVID-19 pandemic, we have incorporated reflection on aspects such as video games, comics and illustration. Among the contributions of this process we highlight the creation of a set of audiovisual capsules, in which specialists and teachers, both from the university and high school, present their points of view, covering current issues, and involving current creatives. These initiatives make it possible to bring together environments that traditionally remained distant, such as university departments and secondary schools. We want to promote cooperation between university and secondary school, generating resources for students and teachers, incorporating digital technologies. In the opinions collected through surveys and analysis of results, also coordinating focus groups, we detected that the work serves to transmit energy to both teachers and students.

Keywords: Video games, Secondary School, Art Education,
Creativity, Digital Technology

\section{INTRODUCCIÓN}

Durante el curso 2020-2021 hemos continuado con el proyecto "Second Round: Arte y Lucha en Secundaria", después de cinco ediciones consecutivas, centrándonos en cuestiones tan valoradas por el alumnado como son los videojuegos, el cómic y la ilustración. El proyecto "Second Round" lleva cinco ediciones consecutivas intentando mejorar la situación de las artes en secundaria, incidiendo en la formación de docentes, y activando actuaciones con el alumnado en los centros. En cada edición hemos priorizado una temática, siempre incorporando cuestiones vinculadas a las TIC, temas de Diseño, así como cine y audiovisuales (Errázuriz Larraín \& Fermandois-Schmutzer, 2021). El curso 2019-2020 incorporábamos el arte efímero, como elemento de integración educativa en el centro. También la creación de una unidad de investigación mixta interuniversitaria llamada "Efímere" nos impulsa a promover el estudio de innovaciones educativas en el campo de las artes visuales.

En el curso 2020-2021 hemos adecuado la propuesta, incidiendo en las posibilidades del cómic, la ilustración y los videojuegos, como líneas de actuación estratégica. Hemos valorado concretamente los siguientes aspectos, planteados como objetivos de las acciones:

1- Elaborar material y diseño de estrategias para la docencia virtual y la evaluación en línea.

2- Organizar, desarrollar y evaluar la docencia.

3- Impulsar las buenas prácticas docentes, actualizando la docencia y las metodologías activas para el aprendizaje.

4- Diseñar estrategias para la incorporación de los ODS a la docencia. 
El proyecto "Second Round" forma parte de las iniciativas para mejorar la calidad docente implementando metodologías, instrumentos metodológicos y técnicas de enseñanzaaprendizaje innovadoras. Debido a la trayectoria y los resultados que llevamos conseguidos después de cinco ediciones del Second Round, podemos plantear nuevos objetivos y mejoras, así como acciones encaminadas a implantar y evaluar el impacto sobre la docencia de las acciones desarrolladas en el proyecto inicial.

Tanto el profesorado como el alumnado han estado implicados al máximo en todas las ediciones del proyecto. La mayoría de los componentes del equipo imparten clase en la Universitat de València y en centros de Secundaria (Ricardo Domínguez, Jesús Hernandis, Ismael Lozano, Ester Ventura, Amparo Alonso, Ricard Ramon, Paloma Rueda, Concha Daud, David Mascarell, María Dolores Soto González, Carmen María Belmonte, Víctor Parral, Olga Olivera Tabeni y Consuelo Piqueres). Siempre hemos establecido contacto con diferentes universidades, por lo que contado con la colaboración de Fernando Hernández (Universidad de Barcelona), María José Gómez Aguilella (VIU), María Vidagañ (Universidad de Zaragoza), Emilio Martínez (Universidad Politécnica de Valencia), Rosabel Roig (Universidad de Alicante), Rafael Sumozas (Universidad de Castilla La Mancha) y María Dolores Arcoba (Florida Universitaria).

Nos anima el interés por renovar las posibilidades que aporta la investigación y la enseñanza de la imagen a los entornos educativos (Escaño, 2019), planteando la posibilidad de generar espacios propicios para difundir el conocimiento del cómic, el libro ilustrado en todas sus vertientes (libro laboratorio, libro performático, libro de artista online, libro objeto, libro conceptual, álbum ilustrado), y también todo aquello vinculado a los videojuegos, uno de los espacios virtuales en el que pasan más horas las generaciones adolescentes. Todo ello con la intención de elaborar nuevas miradas y generar posibilidades online para programar el futuro, como prácticas creativas a los entornos formativos, especialmente en el ámbito de la Educación Secundaria (Huerta \& Domínguez, 2020). Queremos generar un espacio de reflexión sin perder de vista el espíritu de colaboración y la implicación del alumnado y el profesorado de los institutos. Procuramos animar todos los ámbitos docentes, tanto desde la perspectiva educativa como desde la universidad y el mundo académico, ya que nuestro interés consiste en potenciar la situación actual de la educación artística, ampliando el conocimiento de las imágenes, fomentando la alfabetización visual (Duncum, 2015).

Defendemos el uso del cómic, la ilustración y los videojuegos desde la perspectiva de las artes, con una premisa amplia y de carácter integrador. En estudios anteriores hemos venido analizando la situación, animando al profesorado, emparentando las prácticas artísticas con la enseñanza de la imagen. Establecemos diferentes propuestas de actuación tanto por parte del profesorado de artes visuales como de otras áreas de conocimiento, incidiendo en cuestiones de género y diversidad, acercándonos al diseño sostenible (Rolling, 2017). También impulsamos un estudio de estas realidades amparándonos en el paradigma de la cultura visual y en el amplio espectro de los estudios culturales (Mirzoeff, 2006). Insistimos en la necesidad de abordar las artes de manera multidisciplinar, teniendo en cuenta el valor de las imágenes. Por este motivo, los medios de comunicación son fundamentales como materia de estudio desde la perspectiva de las imágenes. Y por eso el cómic, la ilustración, y especialmente los videojuegos resultan tan actuales e interesantes. También apostamos por una visión educativa transdisciplinar, muy pendiente de las cuestiones de género (Butler, 2010), de la diversidad (Mérida Jiménez, 2020), y de la convivencia participativa (Giroux, 2018).

\section{CONTEXTO}

La presencia del cómic, la ilustración y los videojuegos forma parte de nuestras vidas, a todos los niveles, especialmente en cuanto a manifestaciones mediáticas se refiere (Briggs \& Burke, 2009), desde libros y revistas hasta la televisión y los videojuegos, ya que nuestra situación actual favorece la interconexión, desde la modalidad de los llamados hipertextos. Esta circunstancia privilegiada nos hace usuarios y productores habituales de imágenes, lo que supone un elemento de primera magnitud con respecto a innovación, producción industrial, consumo y cultura visual (Karpati, Freedman, Castro, KallioTavin \& Heijnen, 2017). El proceso de crear imágenes, ilustraciones, diseñar videojuegos, nos anima a pensar que se puede y se debe educar en este sentido, asumiendo que la práctica de las artes es una tarea creativa. Actualmente está tomando gran fuerza la producción de entornos educativos. El hecho de generar espacios innovadores desde las artes está directamente ligado a la percepción como principio organizador. Disfrutar de las artes y de las imágenes en general es una de las acciones humanas más beneficiosas, ya que consiste en mejorar los diferentes elementos que configuran nuestra vida a través de la creación de entornos. Por tanto, reflexionar sobre la situación actual de la investigación y la educación artística es una cuestión de marcada importancia.

Durante el curso 2020-2021, el proyecto "Second Round Arte y Lucha en Secundaria" ha vuelto a implicar a ocho universidades, quince centros de Secundaria, al profesorado y al alumnado, en una iniciativa que cohesiona numerosas instituciones y personas, por lo que impulsamos las artes visuales entre un público que cada vez utiliza con más fuerza las imágenes, lo visual. Nos sentimos artesanos de la imagen (Sennett, 2009). En este contexto, los videojuegos, como manifestación de entretenimiento de corte tecnológico, y como la industria cultural más importante de la historia, tienen mucho que aportar a nuestras investigaciones. Además de preocuparnos por el valor educativo que pueden tener los videojuegos, entendemos que fomentar la participación es un tema apasionante para docentes especialistas en artes, y en todas las materias del currículo. Y si queremos que se impliquen los y las adolescentes, los videojuegos serán un buen argumento de interacción.

\subsection{Antecedentes del Second Round}

En su primera edición, en el curso 2015-2016, quince centros de secundaria valencianos, en colaboración con la Universitat de València, se unieron para llevar adelante un proyecto expositivo itinerante, complementado con conferencias, actuaciones artísticas y conciertos, que culminó en una muestra final en el Centro Cultural La Nau. A partir de una propuesta de Creari, grupo de Investigación en Pedagogías Culturales (GIUV2013-103) "Second round. Arte y lucha en Secundaria" ha sido un ejemplo de coordinación y de unión de esfuerzos para una misma causa; y también un proyecto que promueve la emancipación de pensamiento, la cooperación interseccional, y los avances en materia de tecnologías educativas. 
Los profesionales de la educación artística somos conscientes de la pérdida progresiva que está teniendo la práctica artística en el currículum escolar, en la enseñanza obligatoria. También somos responsables de marcar una nueva estrategia de trabajo teniendo en cuenta las necesidades actuales. Para innovar debemos contar con las previsiones de cambios que pueden ocurrir en el futuro. Con la intención de mejorar el panorama actual nos marcamos una serie de objetivos prioritarios:

1. Generar un espacio de encuentro para los profesionales de la Educación Artística.

2. Fomentar un espíritu colectivo integrador entre el profesorado de Secundaria.

3. Facilitar un mayor acercamiento entre el alumnado universitario que está recibiendo la formación inicial de profesorado de dibujo y la formación continuada de los profesores que están trabajando en los institutos

4. Establecer procesos de comunicación online entre el colectivo de profesorado y los estudiantes de Educación Secundaria, diseñando planes de acción para el fomento de la educación digital y el uso crítico de imágenes (Rodríguez Ortega, 2018).

5. Motivar al profesorado y al alumnado construyendo redes de interlocución válidas para los diferentes ámbitos geográficos y de nivel educativo (Bourriaud, 2009).

6. Crear una red entre los centros de Secundaria para estimular nuevas indagaciones animando al profesorado en materia de investigación educativa.

8. Elaborar documentos para marcar unas líneas prioritarias de trabajo de cara a impulsar la educación artística, ateniéndonos a criterios curriculares más avanzados e innovadores (Irwin \& O'Donoghue, 2012).

9. Implicar a las TIC en la nueva concepción de la generación y difusión de las imágenes.

Para llevar a cabo estas intenciones prioritarias queremos desarrollar algunas acciones:

a. Propiciar una red online del profesorado de secundaria de distintas especialidades.

b. Generar web interactivas que cuenten con la difusión por parte de los participantes en redes sociales (Facebook, Twitter, Instagram, Tik Tok)

c. Convocar reuniones con representantes de los diferentes centros con el fin de organizar una red participativa

Con estas ideas nació "Second Round". Hemos conseguido consolidar la red de contactos con el profesorado de secundaria de la especialidad de dibujo y de otras especialidades. Han aumentado los ánimos y la capacidad de gestionar actividades, con un grado de entusiasmo importante por parte del profesorado.

Estamos fomentando nuevas prácticas educativas entre el profesorado:

- Organizando Jornadas de Investigación en Educación Artística.

- Recopilando las acciones desarrolladas en los centros.
- Impulsando la investigación entre el profesorado de secundaria, en colaboración con docentes e investigadores universitarios (Panciroli, 2016).

- Implicando al alumnado en una serie de acciones para promover el contacto con docentes.

Uno de los resultados más difundidos es el Second Round Movie: Líneas, corto dirigido por Emilio Martí López en el que han participado alumnado y profesorado de los institutos de valencianos. Líneas es una película reivindicativa donde se incorpora claramente la metodología participativa, puesto que es desde la cooperación que ha sido posible realizarla.

\section{DESCRIPCIÓN}

La metodología que impulsamos se basa en un modelo cualitativo de investigación muy centrado en los estudios de caso (Stake, 1995; Yin, 2009). Queremos favorecer las narrativas de vida y motivar al profesorado en un proceso de investigación-acción que pondrá en valor lo que se está haciendo en centros, al tiempo que propiciará un mayor acercamiento a los intereses del alumnado, siempre muy motivados cuando optamos por las tecnologías digitales y la creación de imágenes, algo que conlleva el trabajo con videojuegos.

Durante el curso 2017-2018 las acciones del "Second Round: Arte y lucha en cerámica y diseño", significaron un acercamiento a la Escuela de Arte y Superior de Diseño (EASD Valencia), y también a la Escuela de Arte y Superior de Cerámica (EASC Manises), generando unas Jornadas, un libro, un monográfico de la revista EARI y una exposición. Cabe destacar que en 2018 se defendió la tesis doctoral con mención internacional Comunicar el arte a la educación Secundaria. El proyecto Second Round, presentada por María José Gómez Aguilella, que recibió la máxima calificación de Sobresaliente Cum Laude. También queremos destacar la importancia los numerosos artículos que se están publicando en revistas de investigación, así como de los libros editados.

La incorporación de los videojuegos y sus posibilidades educativas en el contexto de secundaria convierte el proyecto "Second Round" una propuesta innovadora, ya que no se había abordado previamente desde la perspectiva de la investigación universitaria. Hay antecedentes en ámbitos por separado, pero en este caso, como que se está combinando el pensamiento educativo desde las TIC, con una fuerte carga de ocio cultural, que particulariza la propuesta, tenemos una apuesta de marcado carácter transdisciplinar, ya que combina áreas de conocimiento $\mathrm{y}$ de interés tan variadas como son las siguientes: Comunicación, Creatividad, Ocio, Pedagogía, Psicología, Tecnología, Humanidades, Arte, Filosofía, Sociología, Educación y TIC. Lo que queremos es integrar los conceptos de investigación, creatividad y educación tecnológica en el ámbito de las artes y la cultura visual, a fin de revisar lo hecho hasta ahora en esta materia, y sobre todo gestionar propuestas de futuro. El éxito de anteriores convocatorias avala este nuevo encuentro académico de calado interseccional.

Podemos encontrar múltiples definiciones tanto del término videojuego como de creatividad en la bibliografía extensa de la temática, especialmente en el ámbito anglosajón y los textos publicados en inglés. Asimismo, la tradición de los Estudios Culturales, de gran implantación en las universidades norteamericanas y en Latinoamérica es la que nos acerca tanto 
a la cultura visual como las pedagogías culturales desde el ámbito de la creatividad (Hamlin \& Fusaro, 2018). Defendemos el uso de las TIC de la perspectiva de las artes, de las tecnologías de la imagen y de los audiovisuales, de la educación y las humanidades, con una premisa amplia y de carácter integrador. Impulsamos un estudio de estas realidades amparándonos en el paradigma de la cultura visual y en el amplio espectro de los estudios culturales y del fomento de la creatividad. Insistimos en la necesidad de abordar los videojuegos de manera unificada, incorporando tanto las artes como los audiovisuales, y por supuesto la creatividad del alumnado adolescente, pero teniendo en este caso los videojuegos como punto de mira. En la actualidad apostamos por una visión transdisciplinar, muy pendiente de las cuestiones de género, de la diversidad (Greteman, 2017), y de la convivencia en colaboración y participativa (Freire, 2015).

\section{RESUltados}

La cultura de los videojuegos ha pasado a formar parte del imaginario colectivo. Igual como las humanidades y las artes, como el cine y la televisión, los videojuegos forman parte de nuestras vidas a todos los niveles, especialmente desde que las TIC han dado acceso inmediato a la visión, la producción y la difusión de creaciones de imaginarios visuales a través de plataformas tan populares y generalizadas como las redes sociales, y evidentemente desde que tenemos acceso a dispositivos que nos permiten disfrutar de las sucesivas versiones que van apareciendo de cada juego. Esta circunstancia privilegiada nos hace usuarios y productores habituales de creaciones tecnológicas y culturales, lo que supone un elemento de primera magnitud con respecto a innovación, producción industrial, consumo y cultura visual. El proceso de crear y difundir cultura a través de las plataformas online proporciona una estructura y un orden concretos. Hay que avanzar en la línea del uso de las TIC, al menos en tres direcciones: 1) Entendiendo que se puede y se debe educar en TIC; 2) Asumiendo que la práctica de las artes es una tarea creativa; 3) Educando en el uso y disfrute de las tecnologías.

Actualmente ha tomado gran fuerza la producción de imágenes por parte de numerosos usuarios, especialmente del público más joven. El hecho de crear productos culturales, imágenes y audiovisuales, está directamente ligado a la percepción como principio organizador. Crear y disfrutar de las imágenes, interactuar de forma lúdica en los videojuegos, es una de las acciones humanas que pueden resultar más beneficiosas, ya que consiste en mejorar los diferentes elementos que configuran nuestra vida a través de las imágenes y de las interacciones, a través de la comunicación y del ocio. Por tanto, reflexionar sobre la situación actual de la investigación y la educación en un elemento del entretenimiento como los videojuegos es una cuestión de marcada importancia.

Nos acercamos al uso y la creación de videojuegos atendiendo a la creatividad, desde la perspectiva del Horizonte 2020 (H2020), el Programa Marco de la Comisión Europea para la investigación y la innovación, ya que se trata de una actividad basada completamente en el interés por la innovación, una iniciativa pensada para asegurar la competitividad de Europa a nivel global. Este tipo de interacciones une a representantes de la sociedad civil, del mundo de la empresa y del mundo académico, planteando la excelencia científica, impulsando la investigación de primer nivel. También constituye un reto social, ya que ante una sociedad cada vez más envejecida (muy especialmente la europea), se trata de fomentar el emprendimiento tecnológico entre los más jóvenes. Estimulamos la cooperación potenciando nuevas estrategias que permitan un enfoque diferente (Pook, 2020), rompiendo cualquier barrera de cara a la creación de un mercado real para el conocimiento, la investigación y la innovación. En cuanto al reparto de responsabilidades de manera equitativa, hacemos un especial énfasis en los equilibrios de género.

Uno de los espacios online en el que se puede encontrar el Proyecto Second Round es el MODE Museo Officina dell'Educazione de la Universidad de Bolonia http://www.doc.mode.unibo.it

Un buen ejemplo del tipo de acciones que planteamos se puede encontrar en las "Píldoras Second Round", un conjunto de 17 cápsulas audiovisuales en las que el alumnado y el profesorado de secundaria encontrarán numerosos ejemplos de actividades y propuestas en las que se plantean los beneficios de los videojuegos, el cómic y la ilustración. El enlace en el que se puede acceder a las "Píldoras Second Round" es el siguiente:

\section{https://youtube.com/playlist?list=PLiPJNI1xCP1sqQS77ur-} $\underline{\text { PkeyPiEQdve } 5 z}$

\section{CONCLUSIONES}

En consonancia con los retos sociales que prevé tanto el programa Horizon 2020 de la UE como los ODS de Unesco, entendemos que investigar en materia de videojuegos y creatividad supone enfrentarse a una problemática que afecta a todos los sectores la población, ya que la cultura visual impregna nuestros entornos cotidianos, y el hecho de crear productos innovadores supone también mejorar las condiciones de vida, reflexionando sobre lo que hacemos y lo que desearíamos ser. Desde la investigación y la educación abordamos los retos sociales intentando acabar con la distancia entre el mercado y las necesidades sociales, dando un impulso especial a la aplicación de la investigación, y ayudando a las partes interesadas a transformar la innovación en productos viables incluso para a su posible comercialización. Este enfoque permitirá crear alianzas entre el sector público y el privado, intentando conseguir los recursos necesarios para sacar adelante este reto. Unimos recursos y conocimiento a través de la tecnología y las disciplinas vinculadas a la educación y la cultura, donde se incluyen las ciencias sociales y las humanidades, la tecnología y la comunicación. En el tipo de reflexión que animamos se incluyen actividades que van desde la investigación hasta el mercado, haciendo énfasis en un nuevo enfoque basado en las actividades basadas en la innovación, como son los productos y las demostraciones que actualmente están invadiendo los proyectos educativos más innovadores en todo el mundo.

La estrategia europea se basa en tres pilares: un pilar económico de transición hacia una economía dinámica, competitiva y basada en el conocimiento; un pilar social basado en la inversión en educación y formación y en la lucha contra la exclusión social; y un pilar medioambiental de crecimiento disociado de la utilización excesiva de recursos naturales. Lo cierto es que a estas alturas Europa no es la economía más competitiva del mundo ni goza de pleno empleo, por ello ya se habla de 3 prioridades o motores clave de crecimiento: 1) Crecimiento inteligente, impulsando el conocimiento, la innovación, la educación y la sociedad digital; 2) Crecimiento sostenible de la economía, uso eficaz de los recursos, verde y 
competitiva; y 3) Crecimiento integrador, empleo y cohesión social y territorial. Con estas premisas, pretendemos avanzar en el crecimiento inteligente, impulsando el conocimiento, la innovación, la educación y la sociedad digital. Esta premisa debe estar presente en la educación pública, y debe ser importante para la universidad pública. Deseamos un mayor acercamiento a la realidad que viven las generaciones más jóvenes, a través de los videojuegos, la industria cultural que más ha crecido en los últimos años, y la que más beneficios genera a nivel global, la apuesta por una reflexión sobre lo que está pasando en esta industria cultural en relación al sistema educativo resulta más necesaria que nunca. Si a esta realidad añadimos la situación que ha provocado la pandemia del Covidien-19, entonces comprenderme que no estamos hablando solamente de educación, cultura y entretenimiento, sino que estamos investigando sobre cuestiones que afectan al crecimiento sostenible de la economía, y también al crecimiento integrador, ya que las industrias culturales fomentan el empleo y la cohesión social y territorial.

\section{AgRAdecimientos}

Nuestro agradecimiento al profesorado y alumnado que viene colaborando en el Second Round desde que se inició el proyecto en el curso 2015-2016, manteniendo muy alto el interés y la iniciativa creadora en las sucesivas ediciones del proyecto.

\section{REFERENCIAS}

Bourriaud, N. (2009). The Radicant. New York, NY: Lukas \& Sternberg.

Briggs, A. \& P. Burke (2009). A Social History of the Media. From Gutenberg to the Internet. Cambridge, UK: Polity Press.

Butler, J. (2010). Gender Trouble. Feminism and the Subversion of Identity, New York, NY: Routledge.

Duncum, P. (2015). Transforming Art Education into Visual Culture Education through Rhizomatic Structures. Anadolu Journal of Educational Sciences International, 5 (3), 47-64. https://doi.org/10.18039/ajesi.66849

Errázuriz Larraín, L. \& J. Fermandois-Schmutzer (2021). Formación docente para la educación artística en Chile. El desafío cultural pendiente en las escuelas primarias. Arte, Individuo $\quad y \quad$ Sociedad,33(1), 49-69. https://doi.org/10.5209/aris.67126

Escaño, C. (2019). Biopolitical commons in the postdigital era. Postdigital Science and Education, 1(2), 298-302. https://doi.org/10.1007/s42438-019-00041-2

Freire, P. (2015). Pedagogia da autonomia: saberes necessários à prática educativa. Rio de Janeiro: Paz e Terra.
Giroux, H. (2018). Pedagogy and the politics of hope: Theory, culture, and schooling: Acritical reader. New York, NY: Routledge

Greteman, A. J. (2017). Helping Kids Turn Out Queer: Queer Theory in Art Education, Studies in Art Education: A Journal of Issues and Research, 58(3), 195-205.

Hamlin, J. \& J. Fusaro (2018). Contemporary Strategies for Creative and Critical Teaching in the 21st Century, Art Education, 71(2), 8-15.

Huerta, R. \& R. Domínguez (2020). Por una muerte digna para la educación artística, EARI Educación Artística: Revista de Investigación, 11, 9-24. https://doi.org/10.7203/eari.11.19114

Irwin, R. \& O'Donoghue, D. (2012). Encountering pedagogy through relational art practices. International Journal of Art \& Design Education, 31 (3), 221-236.

Karpati, A., K. Freedman, J. C. Castro, M. Kallio-Tavin \& E. Heijnen (2017). Collaboration in Visual Culture Learning Communities: Towards a Synergy of Individual and Collective Creative Practice, International Journal of Art and Design Education, 36(2), 164-175. https://DOI.org/10.1111/jade.12099

Mérida Jiménez, R. M. (2020). Founding and Ineffable Identities: Pelagius, Virgin and Martyr, Imago temporis. Medium Aevum, 14, 165-184.

Mirzoeff, N. (2006). On Visuality, Journal of Visual Culture, 5(1), 53-79.

Panciroli, C. (2016). Los bienes culturales como patrimonio educativo, EARI Educación Artística Revista de Investigación, $7, \quad 86-99$. https://doi.org/10.7203/eari.7.8158

Pook, Z. S. (2020). The Challenge of Implementing Preferred Gender Pronouns: Queer Autonomy in the Age of Information Technologies, Interalia, 15, 6-16. https://doi.org/10.51897/interalia/BTAW6071

Rodríguez Ortega, N. (2018). Five Central Concepts to Think of Digital Humanities as a New Digital Humanism Project, Artnodes: revista de arte, ciencia y tecnología, 22, 1-6. https://doi.org/10.7238/a.v0i22.3263

Rolling, J. H. (2017). Arts-Based Research in Education. In Leavy, P. (ed.) Handbook of Arts-Based Research, New York: Guilford, 493-510.

Sennett, R. (2009). The Craftsman. London: Penguin Books.

Stake, R. E. (1995). The Art of a Case Study Research. London: Sage Publications.

Yin, R. K. (2009). Case Study Research, London: Sage. 